\title{
Aggression Dimensions in Students with Autism
}

\author{
Elsayed S. Elkhamisi \\ Associate Prof. Psychology \& Special Education Post Graduate College, \\ Arabian Gulf University, Kingdom of Bahrain \\ Maryam Almutery \\ Special Education Teacher, Ministry of Education, State of Kuwait
}

Doi: 10.19044/esj.2018.v14n9p330 URL:http://dx.doi.org/10.19044/esj.2018.v14n9p330

\begin{abstract}
The current study is intended to explore the prevalence of aggression level of students with autism based on gender, age, and intellectual state. The study sample is composed of parents for (108) of children with autism. These students are aged 5-16 years old who have been attending the autism centers in the State of Kuwait. The current study has utilized a three-dimensional aggression scale, which includes aggression toward others, aggression toward self, and aggression toward things. The result of the study reveals that among the participant's aggression toward others has been ranked the highest on subscale, followed by aggression toward self, and lastly aggression toward things. The study further exposed that the most significant aspects of aggression were explicit obstinacy and refusal when asking the participant to perform an action, the act of pinching others in a state of anger, kicking others without any legit or obvious reason, throwing himself on the floor, and hitting himself with his hand or any other part of his body. In addition, the results of the study suggests that there are a statistically significant differences based on gender in aggression toward things, which is in favour of female. No statistically significant difference has been observed based on gender on aggression toward others. As per the total score of aggression scale, there is no statistically significant difference found based on age or intellectual state of all aggression subscales.
\end{abstract}

Keywords: Autism, aggression, gender, intellectual stat

\section{Introduction}

In contemporary medical terminology, autism is commonly described as a disorder, which accounts for significant variability among individuals in their ability to adapt and function normally in their routine daily life. Within the autism spectrum, children may exhibit various combinations of specific 
behaviors ranging enormously in intensity. Moreover, the extent of symptoms and degree of severity may remarkably change over their lifespan. Consequent to this variability, obtaining a proper and an accurate diagnosis of autism is exceedingly complex (Nasr, 2002).

The Diagnostic and Statistical Manual of Mental Disorders Fourth Edition (DSM-IV) (American Psychological Association APA, 2000) described Autism as a sub-category of a Pervasive Developmental Disorder (PPD), which include autistic disorder, Asperger syndrome, Rett Syndrome, disintegrative disorders, and pervasive developmental disorder not otherwise specified (PDD-NOS) (Alice, Carter, Kiln \& Volkmar, 2005). DSM-IV revised the fourth edition is also in line with The International Statistical Classification of Diseases and Related Health Problems (ICD), which has been compiled by the World's Health Organization (WHO). Both have identified three main diagnostic criteria for autism as the proximate symptoms that appear on students with autism. This characteristic triad of symptoms is: impairment in social interaction; impairment in communication; and restricted interest, in-addition to repetitive . These symptoms appear during the first three years of the child's life (Bolet et al., 2011). However, in the fifth edition, they have combined all these different types of disorders under one name, the Autism Spectrum Disorder (ASD), with Ritt's Syndrome coming out of this group, and also determined the onset of symptoms during early childhood, and not during the first three years (American Psychological Association APA, 2013).

Children with autism suffer from numerous challenging behaviors with different levels of intensities. These behaviors are most frequently defined as behaviors of such intensity or duration, during which the physical safety of the person, or others, is to be placed in serious jeopardy. Similarly, behaviors, which can seriously limit the use of, or result in the person being denied access to, ordinary community facilities (Emerson \& Bromley, 1995). Severe challenging behaviors often result in self injury, physical or verbal aggression, shouting or screaming, and refusing to move or to carry out a request may also be observed. However, the first implication of the definition of challenging behaviors is that it is defined by its impact rather than by its topography (Gabriels \& Hill, 2007).

Challenging behaviors can be observed in many forms and may result from a variety of underlying social, psychological, or biological phenomena. However, the behavior is being categorized as challenging based on its consequency, not its frequency. Individuals with challenging behaviors are often inappropriately placed in society (Borthwick-Duffy et al., 1987; Emerson \& Hatton,1994) have a poorer quality of life and have high levels of long-term medication (Mansell, 1994; Sternfert, Dewhurst \& Holmes, 2001). Behaviors such as physical aggression, self-injury, or property destruction can 
threaten an individual's residential placement, interfere with opportunities for social interaction and threaten vocational placement and community participation (Bruininks, Hill \& Morreau, 1988; Larson, 1991; Anderson, Lakin, Hill \& Chen, 1992). The effects of challenging behaviors on caregiver stress and staff turnover have also been well documented in previous literature. Challenging behaviors can pose a significantly negative impact on the health and well-being of the person, intimate caretakers and similarly those who live or work with the person (Russell \& Harris, 1993).

A second implication of the definition of challenging behavior is that the person who has been predicted with the behavior is challenged. Like other forms of impairment, the severe challenging behavior may present barriers to the person's participation in ordinary community living. In this sense, the person has a behavioral disability (Emerson, 1998).

Children with autism have been observed with numerous forms of aggressive behaviors, which can be categorized as aggression toward others, self, and things. Previous studies on the present subject matter showed that children with autism have high level of aggression; such as head banging and self-scratching until bleeding (Le \& Lohr, 2012). Studies further reveal that boys with ASD react with more serious forms of aggression when subjected to mild aggressive attacks and did not consider a child attacker's opposite sex an inhibitory factor. Where're the girls with ASD reacted less aggressively than the girls without ASD. According to the results, boys with ASD may not follow the typical development in cognitive regulation of reactive aggression (Kartinen, Puura, Helminen, Salmelin \& Pelkonen et al., 2014).

\section{Study Problem}

There is variation in the results which described the aggressive behavior of autistic individuals ; some studies indicating that these individuals had high levels of aggression (Bronsard et al., 2010; Kanne \& Mazurek, 2012; Mazurek, Kanne \& Wodka, 2013; McTiernan, Leader, Healy, \& Mannion, 2011; Medeiros, Kozlowski, Beighley, Rojahn, \& Matson, 2012; Murphy Healy \& Leader, 2009), while others showed to low levels of aggression (Hill et all., 2014). Moreover, these studies did not show the differences in level of aggression according to gender, age, or IQ, nor did they detected the manifestations of aggression, such as scratching, biting or kicking to themselves, to others, or to objects.

Hence, the current research problem has emerged in the detection of characteristics or manifestations of aggression in children with autism, and their differences according to age, gender and IQ.

\section{Study questions}

The study attempts to answer the following questions: 

children?

1- What are the characteristics of aggressive behavior in autistic

2- Are there differences in the aggressive behavior of the autistic students according to gender, age and IQ?

\section{Method}

\section{Subjects}

The study sample is composed of (108) students diagnosed with ASD, divided according to: a) gender $\{(82)$ males\& (28) females $\}$; b) age $\{(78)$ children\& (30) adolescents $\}$, and c) presence of intellectual disability (ID) $\{(41)$ with ID\& (67) without ID $\}$ (table 1).

To diagnose the study sample, the present study has used the facility of diagnosis of Developmental Medicine Department in the state of Kuwait for diagnosis of children whether they have autism or intellectual disability or not. The department is considerably depending on the Childhood Autism Rating Scale (CARS) for the diagnosis of autism cases and for identification of its severity .In addition, their procedures depend on the Binet test fourth edition for identifying a child's IQ.

Table 1 Demographic Characteristics of Subjects

\begin{tabular}{llllll}
\hline & $\mathrm{N}$ & $\begin{array}{l}\text { Minimum } \\
\text { age }\end{array}$ & $\begin{array}{l}\text { Maximum } \\
\text { age }\end{array}$ & Mean & $\begin{array}{l}\text { Std. } \\
\text { Deviation }\end{array}$ \\
\hline Gender & 82 & 6.00 & 16.00 & 9.77 & 2.70 \\
Male & 26 & 6.00 & 16.00 & 10.34 & 3.12 \\
$\begin{array}{l}\text { Female } \\
\text { Age stage }\end{array}$ & & & & & \\
Children & 78 & 6.00 & 11.00 & 8.46 & 1.54 \\
$\begin{array}{l}\text { Adolescents } \\
\text { Intellectual }\end{array}$ & 30 & 12.00 & 16.00 & 13.66 & 1.583 \\
$\begin{array}{l}\text { Disability } \\
\text { With }\end{array}$ & & & & & \\
Without & 41 & 6.00 & 15.00 & 8.68 & 2.43 \\
\hline Total & 67 & 6.00 & 16.00 & 10.65 & 2.77 \\
\hline & 108 & 6.00 & 16.00 & 9.91 & 2.81 \\
\hline
\end{tabular}

\section{Scales}

\section{Aggression Scale}

The present study has adopted a measure of aggressive behavior from Syadi ( 2011), for detection of aggressive behaviors observed in children diagnosed with autism disorder and for identification of the forms of aggression they have. The scale is composed of (30) items, which are further classified into three subscales: aggression toward others (14 items), aggression toward self (10 items), and aggression toward things (6 items).

The advantage of aggression scale is that it can equally be applied through observation and interview with a parent or a teacher of the child. The answers were then recorded on one of the scale items within five choices. 
Where choices are given as; always, often, sometimes, rarely, and never which were ranked from 5 to 1 respectively. The validity is accounted by internal consistency, and validity coefficients are ranged between 0.87 and 0.62. Cronbach's alpha coefficient was also accounted to identify the reliability coefficient, which ranged between 0.93 and 0.80 .

\section{Childhood Autism Rating Scale(CARS)}

In the present study, CARS has been adopted by the Developmental Medicine Department in the state of Kuwait to diagnosis children for the prevalence of autism. The advantage of using the CARS scale is that it significantly evaluates children based on several areas related to the implicit symptoms of autism. The scale is further categorized into (15) subscales, which are: Relationship with People, Tradition, and Simulation, Emotional Response, Use of Body, Use of Objects, Adapt to Change, Visual Response, Responses to Listening, Response \& the Use of Test, Smell \& Touch, Fear \& Anxiety or Nervousness, Verbal Communication, Non-Verbal Communication, Level of Activity, Level \& Stability of the Response of Mental, and General Impression. Schopler, Reichler \& Rochen (1988) have reported hight reliability and validity of CARS.

\section{Statistical Analysis}

For quantitative analysis of the phenomenon under consideration, present study utilized statistical tolls of averages and standard deviations to determine the level of subscales and a total score of aggression in children with autism. In addition, One-way analysis of variance has also been carried out to significantly detect differences in the subscales and a total score of aggression among males and females, children and adolescents, and children with autism with and without intellectual disability. All of the statistical analyses were performed using the Statistical Program for Social Sciences (SPSS), Version 20.0.

\section{Results}

\section{Prevalence of Aggression}

To identify the level of aggression for the sample means and standard deviations, they are calculated for subscales and a total score of aggression scale (table 2 and figure 1). Because the means of the subscales are not unified they are standardized by the following equation:

Mean of the dimension

Number of items 
Table 2. Mean, standard deviation and standard means for aggression subscales and the total score

\begin{tabular}{ccccc}
\hline Subscales & $\mathrm{N}$ & Mean & Std. Deviation & Std. Means \\
\hline Toward others & 108 & 29.95 & 12.84 & 29.95 \\
Toward self & 108 & 16.93 & 7.83 & 23.703 \\
Toward things & 108 & 11.38 & 6.15 & 26.58 \\
\hline
\end{tabular}

The results suggest that the aggression toward others has been the highest on the subscale, followed by aggression toward self, and then by aggression toward things.

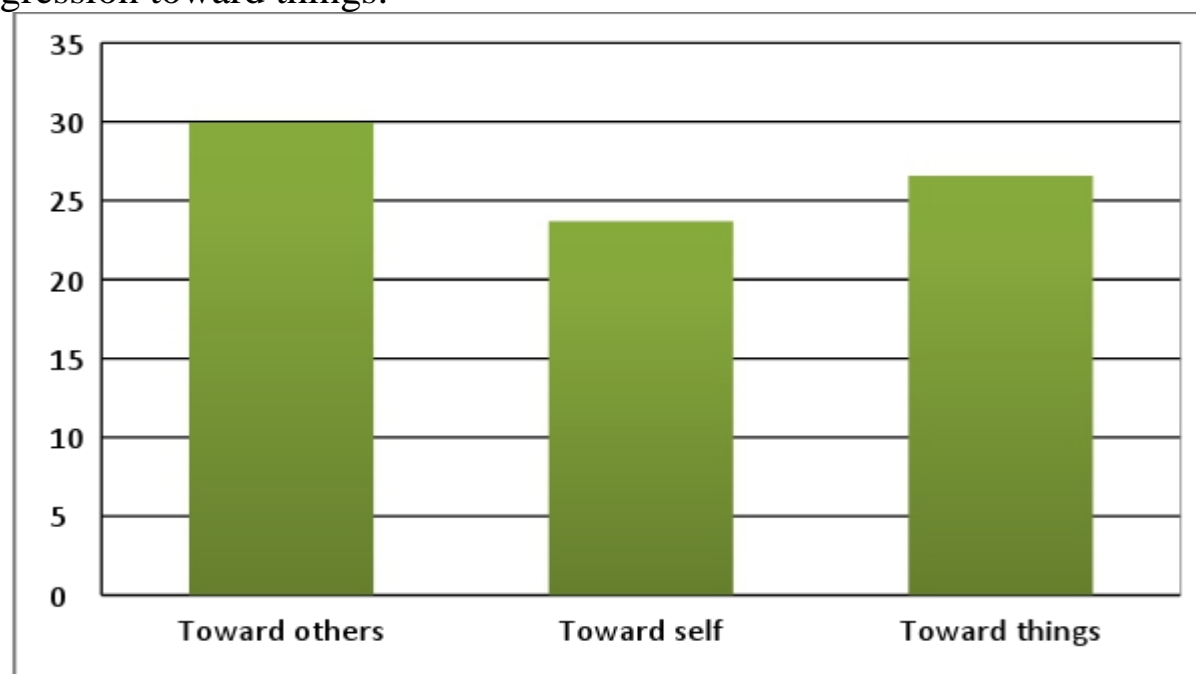

Figure 1. The profile of aggression for students with autism

To explore the aggression characteristics of autistic students, means are calculated for items of each subscale of aggression scale, table 3 shows means of the three highest items in each subscale.

Table 3 Means of the three highest items in each subscale

\begin{tabular}{lll}
\hline Subscale & Phrase & Means \\
\hline Toward other & Biting others when becomes angry & 2.44 \\
& kicking others for no apparent reason & 2.35 \\
& Hitting others even if they are not the cause of their & 2.32 \\
& anger. & \\
Toward things & Breaking the furniture. & 2.10 \\
& Breaking the school tools during the lesson & 1.97 \\
& Tearing own clothes in anger & 1.96 \\
Toward self & Strong self scratching to the point of leaving a trace of & \\
& blood on the skin & 2.28 \\
& Use of sharp materials in self injury & 2.13 \\
& Head hitting on the wall or any solid object & 1.81 \\
\hline
\end{tabular}

\section{Differences between Gender}

Mean and standard deviation for aggression subscale are accounted for males $(\mathrm{N}=82)$ and females $(\mathrm{N}=26)$, Table 4. 
Table 4 Mean and standard deviation for aggression subscale according to gender

\begin{tabular}{lllll}
\hline Gender & Aggression & N & M. & SD. \\
\hline \multirow{4}{*}{ Male } & Toward others & 82 & 29.83 & 13.12 \\
& Toward self & 82 & 17.14 & 8.53 \\
& Toward things & 82 & 12.14 & 6.42 \\
& Total aggression & 82 & 59.12 & 25.93 \\
\cline { 2 - 5 } Female & Toward others & 26 & 30.34 & 12.13 \\
& Toward self & 26 & 16.26 & 5.11 \\
& Toward things & 26 & 9.00 & 4.56 \\
& Total aggression & 26 & 55.61 & 18.36 \\
\hline
\end{tabular}

Table 4 document the results based on gender differences. It revealed that aggression toward others has been placed the highest on the scale (male: mean 29.83, SD 13.12, female: Mean 30.34, SD 12.13), followed by aggression toward self (male: mean 17.14, SD. 8.53, female: Mean 16.26, SD 5.11). Finally, aggression toward things was ranked at the lowest place (male: mean 12.14, SD. 6.42, female: Mean 9.00, SD 4.56), while the total score on a scale aggression was (male: mean 59.12, SD25.93, female: Mean 55.61, SD 18.36). One-way analysis of variance ANOVA) has been utilized to determine the differences between males and females, table 5 .

Table 5 Results of ANOVA for differences between males and females at aggression subscale

\begin{tabular}{lllllll}
\hline & & Sum of Squares & DF & Mean Square & F & Sig. \\
\hline \multirow{2}{*}{$\begin{array}{l}\text { Toward } \\
\text { others }\end{array}$} & Between Groups & 5.274 & 1 & 5.274 & .032 & .859 \\
& Within Groups & 17637.494 & 106 & 166.391 & & \\
\multirow{5}{*}{ Toward self } & Total & 17642.769 & 107 & & & \\
& Between Groups & 15.187 & 1 & 15.187 & .246 & .621 \\
& Within Groups & 6555.359 & 106 & 61.843 & & \\
Toward & Total & 6570.546 & 107 & & & \\
things & Between Groups & 195.423 & 1 & 195.423 & 5.361 & .023 \\
& Within Groups & 3864.244 & 106 & 36.455 & & \\
Total & Total & 4059.667 & 107 & & & \\
aggression & Between Groups & 242.732 & 1 & 242.732 & .409 & .524 \\
& Within Groups & 62902.934 & 106 & 593.424 & & \\
\hline
\end{tabular}

The outcomes of the analysis of variance procedures suggest that there are a statistically significant differences between males and females on aggression toward things, which favour females $(F=5.36$, Sig $0.023<0.05)$. However, there are no confirmed statistically significant differences between them based on aggression toward others $(F=0.032$, Sig $0.859>0.05)$, toward self $(F=0.246$, Sig $0.621>0.05)$, or for the total score for aggression scale ( $F$ $=0.409$, Sig $0.524>0.05)$. 


\section{Differences between Age groups}

Mean and standard deviation for aggression dimensions for children and adolescents given in table 6 .

Table 6 Mean and standard deviation of aggression dimensions for children and adolescents

\begin{tabular}{lllll}
\hline Age Stages & \multicolumn{1}{c}{ Aggression } & N & Mean & Std. Deviation \\
\hline \multirow{4}{*}{ Children } & Toward others & 78 & 30.34 & 12.62 \\
& Toward self & 78 & 16.93 & 7.87 \\
& Toward things & 78 & 11.96 & 6.33 \\
& Total aggression & 78 & 59.24 & 24.24 \\
\cline { 2 - 5 } Adolescents & Toward others & 30 & 28.93 & 13.54 \\
& Toward self & 30 & 16.93 & 7.87 \\
& Toward things & 30 & 9.90 & 5.49 \\
& Total aggression & 30 & 55.76 & 24.65 \\
\hline
\end{tabular}

According to the results presented in table 6, there is equality to the subscale of the order of both age groups, it was the aggression toward others which has been ranked at first place (children: mean 30.34, SD 12.62, adolescents: Mean 28.93, SD 13.54), followed by aggression toward self (children: mean 19.93, SD. 7.87, adolescents: Mean 16.93, SD 7.87). Finally aggression toward things (children: mean 11.96, SD. 6.33, adolescents: Mean 9.90, SD 5.49). While the total score on a scale aggression was (children: mean 59.24, SD 24.24, Adolescents: Mean 55.76, SD 24.65). One-way analysis of variance ANOVA was used to account the differences between children and adolescents as shown in table 7

Table 6 Results of ANOVA for differences between children and adolescents at aggression subscale

\begin{tabular}{|c|c|c|c|c|c|c|}
\hline & & $\begin{array}{l}\text { Sum of } \\
\text { Squares }\end{array}$ & Df & $\begin{array}{l}\text { Mean } \\
\text { Square }\end{array}$ & $\mathrm{F}$ & Sig. \\
\hline \multirow{4}{*}{$\begin{array}{l}\text { Toward } \\
\text { others }\end{array}$} & Between & 43.248 & 1 & 43.248 & .260 & .611 \\
\hline & Groups & & & & & \\
\hline & Within Groups & 17599.521 & 106 & 166.033 & & \\
\hline & Total & 17642.769 & 107 & & & \\
\hline \multirow{4}{*}{$\begin{array}{l}\text { Toward } \\
\text { self }\end{array}$} & Between & .000 & 1 & .000 & .000 & .999 \\
\hline & Groups & & & & & \\
\hline & Within Groups & 6570.546 & 106 & 61.98 & & \\
\hline & Total & 6570.546 & 107 & & & \\
\hline \multirow{4}{*}{$\begin{array}{l}\text { Toward } \\
\text { things }\end{array}$} & Between & 92.082 & 1 & 92.082 & 2.46 & .12 \\
\hline & Groups & & & & & \\
\hline & Within Groups & 3967.585 & 106 & 37.430 & \multirow{6}{*}{.442} & \multirow{6}{*}{.508} \\
\hline & Total & 4059.667 & 107 & & & \\
\hline \multirow{4}{*}{$\begin{array}{l}\text { Total } \\
\text { aggression }\end{array}$} & Between & 261.928 & 1 & 261.928 & & \\
\hline & Groups & & & & & \\
\hline & Within Groups & 62883.738 & 106 & 593.243 & & \\
\hline & Total & 63145.667 & 107 & & & \\
\hline
\end{tabular}

According to the results presented in table 6, there is no statistically significant differences between children and adolescents on all aggression subscale; toward others $(F=0.260$, Sig $0.611>0.05)$, towards self $(F=0.000$, 
Sig $0.999>0.05)$ towards things $(F=0.46$, Sig $0.12>0.05)$, or total score for aggression scale $(\mathrm{F}=0.442$, Sig $0.508>0.05)$.

\section{Differences between children with and without intellectual disability:}

Mean and standard deviation for aggression subscale was calculated for children's with and without intellectual disability, Table 7.

Table 7 Mean and standard deviation of aggression subscale based on intellectuality state

\begin{tabular}{lllll}
\hline $\begin{array}{l}\text { Intellectual } \\
\text { Disability }\end{array}$ & \multicolumn{1}{c}{ aggression } & $\mathrm{N}$ & Mean & Std. Deviation \\
\hline With & Toward others & 67 & 30.02 & 12.85 \\
& Toward self & 67 & 16.86 & 7.56 \\
& Toward things & 67 & 10.97 & 5.89 \\
& Total aggression & 67 & 57.86 & 24.37 \\
\cline { 2 - 5 } Without & Toward others & 41 & 29.82 & 12.97 \\
& Toward self & 41 & 17.04 & 8.35 \\
& Toward things & 41 & 12.07 & 6.58 \\
& Total aggression & 41 & 58.95 & 24.44 \\
\hline
\end{tabular}

Results presented in table 7 reveal that there is equality in the subscale of the order of both age groups. Aggression toward others has been placed first (with ID: mean 30.02, SD 12.85, without ID: Mean, 29.82, SD 12.97), followed by aggression toward self (with ID: mean 16.86, SD. 7.56, without ID: Mean 17.04, SD 8.35), and finally aggression toward things is (with ID: mean 10.97, SD 5.89, without ID: Mean12.07, SD 6.58). Where the total score on a scale aggression is (with ID: mean 57.86, SD 24.37, without ID: Mean 58.95, SD 24.44). One-way analysis of variance ANOVA is used to account the differences between children and adolescents as shown in table 8 .

Table 8. Results of ANOVA for differences between children with and without intellectual disability at aggression subscale

\begin{tabular}{|c|c|c|c|c|c|c|}
\hline Aggression & & $\begin{array}{l}\text { Sum of } \\
\text { Squares }\end{array}$ & Df & $\begin{array}{l}\text { Mean } \\
\text { Square } \\
\end{array}$ & $\mathrm{F}$ & Sig. \\
\hline \multirow{3}{*}{$\begin{array}{l}\text { Toward } \\
\text { others }\end{array}$} & $\begin{array}{l}\text { Between } \\
\text { Groups }\end{array}$ & 1.023 & 1 & 1.023 & \multirow[t]{3}{*}{.006} & \multirow[t]{3}{*}{.938} \\
\hline & Within Groups & 17641.745 & 106 & 166.432 & & \\
\hline & Total & 17642.769 & 107 & & & \\
\hline \multirow{3}{*}{$\begin{array}{l}\text { Toward } \\
\text { self }\end{array}$} & $\begin{array}{l}\text { Between } \\
\text { Groups }\end{array}$ & .853 & 1 & .853 & \multirow[t]{3}{*}{.014} & \multirow[t]{3}{*}{.907} \\
\hline & Within Groups & 6569.693 & 106 & 61.978 & & \\
\hline & Total & 6570.546 & 107 & & & \\
\hline \multirow{3}{*}{$\begin{array}{l}\text { Toward } \\
\text { things }\end{array}$} & $\begin{array}{l}\text { Between } \\
\text { Groups }\end{array}$ & 30.946 & 1 & 30.946 & \multirow[t]{3}{*}{.814} & \multirow[t]{3}{*}{.369} \\
\hline & Within Groups & 4028.721 & 106 & 38.007 & & \\
\hline & Total & 4059.667 & 107 & & & \\
\hline \multirow{3}{*}{$\begin{array}{l}\text { Total } \\
\text { aggression }\end{array}$} & $\begin{array}{l}\text { Between } \\
\text { Groups }\end{array}$ & 29.973 & 1 & 29.973 & \multirow[t]{3}{*}{.050} & \multirow[t]{3}{*}{.823} \\
\hline & Within Groups & 63115.693 & 106 & 595.431 & & \\
\hline & Total & 63145.667 & 107 & & & \\
\hline
\end{tabular}


Results presented in table 8 exposed that there is no statistically significant differences between children with and without intellectual disability on all aggression subscales; toward others $(F=0.006$, Sig 0.938> $0.05)$; toward self $(\mathrm{F}=0.014$, Sig 0.907>0.05); toward things $(\mathrm{F}=0.814$, Sig $0.369>0.05)$, or total score for aggression scale $(F=0.050$, Sig $0.823>0.05)$.

\section{Discussion}

The overall in-depth analysis of the results suggests that the aggression toward others has been placed highest on the subscale, followed by aggression toward things, and finally aggression toward self. The proximate reason for the highest aggression toward others can rightly be traced in insignificant or no interaction of the child or adolescent diagnosed with autism with other people. Most of the time the autistic students demands things, which they cannot get without other peoples help or because they want to avoid doing things that, someone else wants them to do. Thus, a large part of the behavior that adults find so difficult is, at its base, an effort to communicate. It is rare for children, even children with severe autism, to behave badly just to test the patience of others, because such behavior is intrinsically rewarded. It is also, not because children simply want to make life difficult for the adults around them. Instead, children with ASDs often use strategies that they have found, through experience, to be effective in solving immediate problems (Sabapathy, Vanderbilt, Zamora, \& Augustyn, 2016; Durand\& Merges, 2001).

It has been reported by previous researches carried out in the current area of interest, that aggression toward self or self-injurious behavior can explicitly be observed in approximately $50 \%$ of children with autism spectrum disorders (Richards, Oliver, Nelson\& Moss, 2012). The present study explicitly concludes that the most aggressive behavior's characteristics were biting others when s/he becomes angry, kicking others for no apparent reason, and hitting others even if s/he is not the cause of his or her anger. These results agree with the observations of some parents that the aggression directed toward others by their children with autism during temper tantrums was a product of their frustrated attempts at communication. It perhaps in communication or denial of a want, progressing through a series of escalating difficult behaviors to a full-blown aggression. The aggression may take such forms as prolonged bouts of screaming, punctuated by kicking, hitting, biting, spitting and pushing other people (Matson \& Adams, 2014).

The parents also noted that the aggression toward others or things and challenging behaviors of their autistic children occur because of many situations such as:

- Disruptions in daily routines

- Interruption of enjoyable activities 
- Crowds of people, especially in small spaces

- The presence or approach of strangers

- Too many instructions at once

- Insistent demands from an adult

- Times when there is nothing to do (e.g., while driving a car, sitting in a waiting room).

- Particular sounds, bright lights, or other unpleasant sensory stimulation (O Brien \& Daggett, 2006).

Aggression toward things mostly takes the form of breaking the furniture, breaking the school tools during the lessons, and tearing own clothes in anger. While the most characteristics of aggression toward self were strong self-scratching to the point of leaving a trace of blood on the skin, using sharp materials to elicit self-injury, and head hitting against the wall or any other solid object. The aggression toward things or others, and especially toward self, occurs consequent to many factors such as chemical disturbances in the brain, and some genetic defects. These lead to a deficiency in neurotransmitters such as dopamine, and serotonin which may lead to many types of aggressive behaviors, and also found that the deficiency in the adrenaline hormone, which causes hyper response to external stimuli and may lead to the self-harming behavior. Sometimes this behavior produces a response at the biochemical level whereby naturally occurring opiates like morphine are released into the bloodstream, and this leads to an increased sense of well-being (Sener et al., 2017; Bonander, Beckman, Janson \& Jernbro, 2016; Parikh, Kolevzon \& Hollander, 2009).

Many parents have reported their legit distress at observing their child deliberately injures him- or herself. Even when they suspect that this is a manipulative form of attention seeking, they still find themselves unable to quell their anxiety. Hand-biting, eye-poking, head-banging, and ears lapping are among the most common self-injurious behaviors reported. They are usually shown by children with the most severe form of the disorder. Many explanations exist for this type of behavior, the most common one is that the self-injuring children are simply attention seekers (Sabapathy, Vanderbilt, Zamora \& Augustyn, 2016). Children with autism will usually have many explicit types of skin injuries. Previous studies suggested that the most identified skin injury locations are the legs, knees, and back. Children with autism have skin injuries most frequently and in similar parts of the body (Slingsby, Yatchmink \& Goldberg, 2017).

Children with autism have learned that this behavior, painful as it may be, brings large rewards in terms of adult attention. Another explanation is that the children have learned that causing self injury and pain leads to a sense of well-being. Sometimes the autistic children are showing that they are bored and need stimulation which is explicited in the form of self-injury. It is 
noticeable that the most severe and frequent self-injurious behavior is found in those children who have little or no means of communication. This implies that it is a form of communication and is a trial to interpret the message that the child is attempting to communicate. In ample body of previous work, this behavior indicates that the child or young person feels under some pressure because he or she is no longer in a routine, or because there has been a change in the child handling characteristics (Schweitzer, James, Jenkins, Reiff \& Stein, 2016).

The results of the current study are explicitly in line with many of the previous research in the same area of interest e.g. (Mallory, 2014; Duerden et al., 2012; Ho, Stephenson \& Carter, 2012) which obviously documented that children with autism and with other disabilities experienced significantly greater rates of peer aggression than those in the without disabilities group. Additionally, children with autism and other disability groups were more likely to experience relatively more peer victimization than the other group without a disability. A positive correlation has been observed among peer aggression, autistic traits, anxious/depressed, withdrawn/depressed, thought problems, and attention problems.

Further, the findings reveal that there is no statistically significant difference in aggressive behavior based on gender, age stage (childhood and adolescence) and intellectual disability. This is due to the fact that the autistic child does not do this as his/her desires to hurt himself/ herself, others or things, but this behavior is expressed to indicate that something is wrong; such as a sensual stimulus that cannot be tolerated or processed. Alternatively, patient is exposed to an unorganized or changed environment in a sudden way, or that he/she receives many instructions at the same time, or for one order requiring doing a series of actions (Kanne \& Mazurek, 2012).

The analysis of the this work confirms that there is no statistically significant difference in proximate causes of aggression based on gender, age or in autistic people with or without disabilities. Moreover, most of the teachers, parents, psychologists, workers in the centers, and institutes participated in the study placed significant importance on the reduction of these socially acceptable negative behaviors, because that physically harm the autistic, other individuals in his or her environment. Although this interest is not limited to a specific group of individuals, gender, age group, or those who possess or do not possess an intellectual disability. However, the study findings exposed that aggression toward things was observed relatively more in autistic males than females, and this can be explained in the light of the motor characteristics of males in general, which are characterized by more movement and speed. This hyper movement may make the child being involved in aggressive movements and acts toward things. In addition, males have more opportunities to get out the house than females, exposing them to 
many things and tools that they may not be able to deal with. This increases the chances of aggressive actions toward them, either in order to communicate or to stumble upon them.

\section{References:}

1. Alice, S., Carter, N., Klin, A., and Volkmar, F. (2005). Social development in autism. In F.Volkmar, R.Paul, A.Klin, and Cohen. (Eds). Handbook of autism and pervasive developmental disorders, (3 ed., pp.312-319).Hoboken, NJ: John Wiley and Sons. Canada.

2. American Psychological Association APA. (2013). Diagnostic and statistical manual of mental disorder ( fifth edition) DSM5.Washington ,DC .

3. American Psychological Association APA. (2000). Diagnostic and Statistical Manual of Mental Disorders, 4th Edition, Text Revision, DSM-IV-TR,.Washington ,DC .

4. Anderson, D., Lakin, K., Hill, B. \& Chen, T.(1992). Social integration of older persons with mental retardation in residential facilities. American Journal on Mental Retardation, 96, 488-501.

5. Bolet,S. et al. (2011). Autistic traits and autism spectrum disorders: The clinical validity to tow measures presuming a continuum of social communication skills, Journal of Autism \& Developmental Disorders, 41,66-72.

6. Bonander, C., Beckman, L.,; Janson, S.\& Jernbro, C.(2016). Injury risks in schoolchildren with attention-deficit/hyperactivity or autism spectrum disorder: Results from two school-based health surveys of 6to 17-year-old children in Sweden. Journal of Safety Research, 58: 4965.

7. Borthwick-Duffy et al.(1987). Client characteristics and residential placement patterns. American Journal of Mental Deficiency, 92, 2430.

8. Bronsard, G., Botbol, M. \& Tordjman, S. (2010). Aggression in low functioning children and adolescents with autistic disorder. PLOS ONE 5(12): e14358.

9. Bruininks, R., Hill,B. \& Morreau, L.(1988). Prevalence and implications of maladaptive behaviors and dual diagnosis in residential setting.In: Stark,J.,Menolascino,M., Albarelli,M., \& Gray, V.(eds), Mental retardation and mental health: Classification, Diagnosis, Treatment Services. New York: Springer-Verlag.

10. Duerden, E., Qatley, H., Mak-Fan, K., McGrath, P., Taylor, M., Szatmari, P. \& Robert, S. (2012). Risk factors associated with selfInjurious behaviors in children and adolescent with autism spectrum disorder. J Autism Dev Disord, 42: 2460-2470. 
11. Durand, V.\& Merges, E.(2001). Functional communication training: A contemporary behavior analytic intervention for problem behaviors. Focus on Autism and Other Developmental Disabilities, 16, 110-119.

12. Emerson, E. (1998). Working with people with challenging behavior. Chichester: Wiley.

13. Emerson, E.\& Bromley,j. (1995). The form and function oh challenging bevaviours. Journal of Intellectual Disability Research, 39, 388-389.

14. Emerson,E.\& Hatton,C.(1994). Moving out: The effect of the move from hospital to community on the quality of life of people with learning disabilities. London: HMOS.

15. Gabriels, R. L., \& Hill, D. E. (2007). Growing up with autism: Working with school-age children and adolescents. NewYork: The Guilford Press.

16. Hill et al,. (2014). Aggressive behavior problems in children with autism spectrum disorders: Prevalence and correlates in a large clinical sample. Research in Autism Spectrum Disorders,8 (9), 1121-1133

17. Ho, B., Stephenson, J. \& Carter, M. (2012). Anger in children with autism spectrum disorder: parent's perspective. International Journal of Special Education, 27(2): 223-236.

18. Kanne,S.\& Mazurek,M. (2012). Aggression in children and adolescents with ASD: Prevalence and risk factor . Journal of Autism and Developmental Disorders, 41, 926-937.

19. Kartinen,M., Puura,K., Helminen, M., Salmelin, R., Pelkonen, E., Petri \& Tijdschrift, J. (2014). Samenvatting Reactive aggression among children with and without autism spectrum disorder. Journal of Autism and Developmental Disorders. 4(5), 25-38.

20. Larson, S. (1991). Quality of life for people with challenging behaviours living in community settings. IMOACT, 4(1),4-5.

21. Le, F.\& Lohr, W.(2012). Aggression and Self-Injury in a Patient with Severe Autism, Pediatric Annals 41(10) ,1-3.

22. Mallory, S. (2014). Factors Associated with Peer Aggression and Peer Victimization Among Children with Autism Spectrum Disorders, Children with Other Disabilities, and Children Without a Disability. (Unpublished PhD Dissertations)Columbia University, USA.

23. Mansell, J. (1994). Specialised group homes for persons with severe or profound mental retardation and serious behavior problem in England. Research in Developmental Disabilities, 15, 371-388.

24. Matson, J. \& Adams, H. (2014). Characteristics of aggression among persons with autism spectrum disorder. Research in Autism Spectrum Disorders, 8(11), 1578-1584. 
25. McTiernan A, Leader G, Healy O, Mannion A. Analysis of risk factors and early predictors of challenging behavior for children with autism spectrum disorder. Research in Autism Spectrum Disorders. 5(3):1215-1222.

26. Nasr, S.(2002). Verbal communication for children with Autism. Amman: Dar Elfekr Elaraby.

27. Mazurek, M.\& Kanne S., Wodka, E. (2013). Physical aggression in children and adolescents with autism spectrum disorders. Research in Autism Spectrum Disorders. 9:455-465.

28. Medeiros K., Kozlowski A., Beighley J., Rojahn J.\& Matson J.(2012). The effects of developmental quotient and diagnostic criteria on challenging behaviors in toddlers with developmental disabilities. Research in Developmental Disabilities.33(4):1110-1116.

29. Murphy, O., Healy, O. \& Leader, G.(2009). Risk factors for challenging behaviors among 157 children with autism spectrum disorder in Ireland. Research in Autism Spectrum Disorders. 3(2):474482.

30. Brien, M.\& Daggett, J. (2006). Beyond the Autism diagnosis. London: PAULA BOOOKS Pub.

31. Parikh, M., Kolevzon, A. \& Hollander, E. (2009). Psychopharmacology of aggression in children and adolescents with autism: A critical review efficacy and tolerability. Journal of Child and Adolescent Psychopharmacology, 18(2), 157-178.

32. Richards C, Oliver C, Nelson L, Moss J. (2012). Self-injurious behaviour in individuals with autism spectrum disorder and intellectual disability. Journal of Intellectual Disability Research. 56:476-489.

33. Russell, O. \& Harris, P. (1993). Assessing the prevalence of aggression behaviours and the effectiveness of interventions. In C. Kiernan (ed)), Research to practice: implications of Research on the Challenging Behaviours of people with Learning Disabilities (pp. 60-73). Clevedon: BILD Publication.

34. Sener, E. , Mustafa Caglar Sahin, M., Taheri, S., Bayramov, K.,Marasli, M., Zararsiz, G, Mehmet Canpolat, M., Nilfer Sahin, N. \& Oztop,. D.. (2017). A preliminary study of the genes related to aggression and insensitivity to pain in autism spectrum disorders. Psychiatry and Clinical Psychopharmacology. 27(1), 24-29.

35. Sabapathy, T., Vanderbilt, D., Zamora, I. \& Augustyn, M. (2016). Aggression in Autism Spectrum Disorder: Supporting the entire family. Journal of Developmental and Behavioral Pediatrics. 37(8) 685.

36. Schopler E, Reichler R, Rochen B. (1988). The childhood autism rating scale. Western Psychological Services. 
37. Schweitzer, J.; James, C.; Jenkins, W.; Reiff, M. \& Stein, M. (2016). Acute Agitation and Self-Injury in a 5-Year Old with Autism .Journal of Developmental and Behavioral Pediatrics.37(7) $588: 592$.

38. Seyadi , A. (2011). Level of Aggression level of persons with autism, A project in high diploma in Intellectual disability and Autism, College of Graduate Studies, Arabian Gulf University, Bahrain.

39. Slingsby, B., Yatchmink, Y., Goldberg, A. (2017). Typical Skin Injuries in Children With Autism Spectrum Disorder. Clinical Pediatrics. 56(10) : 942-946.

40. Sternfert,B., Dewhurst, D. \& Holmes, G. (2001). Diagnosis and drugs: Help or hindrance when people with learning disabilities have psychological problems? British Journal of Learning Disabilities, 29, 26-34. 